\title{
PERIODONTAL DISEASE : A RISE IN PREVALENCE IN MILITARY TROOPS PENYAKIT PERIODONTAL
}

\author{
Amaliya Amaliya ${ }^{* * * *}$, Snataka Pribadi ${ }^{* *}$, Yun Mukmin Akbar ${ }^{* *}$, Suhardjo Sitam ${ }^{* * *}$ \\ * Department of Periodontology, Faculty of Dentistry, Universitas Padjadjaran, Bandung, Indonesia \\ ** Indonesian Naval Dental Institute RE Martadinata, Jakarta, Indonesia \\ ** Centre for Military Dentistry Research, Universitas Padjadjaran, Bandung, Indonesia
}

Correspondence: amaliya@fkg.unpad.ac.id

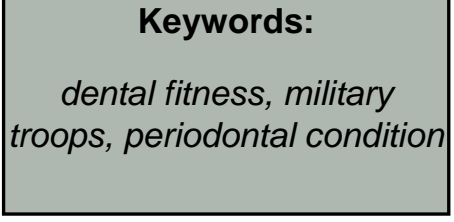

\section{INTRODUCTION}

Oral health is an essential part of human being, it is integral to general health and a determinant factor for quality of life. In the armed forces, oral health influences the health status of military personnel and their readiness to deploy and fight/military operation. The dental readiness and dental fitness of the military personnel have significant impacts on military operations since the untreated oral condition can lead to increase prevalence of disease and non-battle injury for deployed soldiers. ${ }^{1}$ Diseases affecting oral cavity and the system supporting its function can cause impaired duty performance, lost duty time, decrease unit effectiveness, disruption of routine care, hindrance of the military mission, unbearable pain and inability to sleep. Therefore, all active duty personnel need to be in a state of dental as well as physical health, to be ready for extended training, deployment, or war/military operation. In addition to being a force multiplier, dental readiness also contributes to increased morale among personnel. In the last decade, dental emergencies during many conflicts are still a major concern, since they can reduce combat effectiveness. Mostly caused by untreated dental caries and oral surgery related problems, this situation is believed to be preventable by proper diagnosis and prompt 
treatment. ${ }^{2}$ It is evidenced that the rate of dental emergencies is higher for units whose soldiers deploy with poor oral health. ${ }^{3}$

Military dental service has the primary mission in maintaining the dental health of the military personnel at an optimum level to ensure their operation readiness. There has been a decline in dental caries experience in military personnel as a successful outcome of this integrated program. ${ }^{4}$ Most of the members of military division worldwide have both universal access to care and a usual source of care. In addition, they are required to have regular examinations and to maintain a certain level of oral health. ${ }^{5}$ Despite the decline in prevalence of dental decay in military members, periodontal disease is overlooked and has the potential to be a significant health problem among military personnel. In Israeli permanent-force military members, only $1.19 \%$ out of 1300 subjects demonstrated healthy periodontal tissue, despite their obligatory routine medical and dental examination. ${ }^{6}$ In Indian Army Soldiers, the caries experience was considerably low compared with Army population elsewhere, but the need of periodontal treatment was high. ${ }^{7}$ Moreover, a large number of cases (82.7\%) of gingivitis and periodontitis were detected in Pakistan Army population, which shows lack of awareness and self-consciousness among troops regarding their oral hygiene. ${ }^{8}$ Studies from Serbia Army and Thailand military personnel revealed that periodontal condition of the subjects were still below the average.9,10 Furthermore, periodontal reason was still the main cause of tooth loss in a group of Greek Army personnel, reflecting that longevity of the tooth is not achieved. ${ }^{11}$

Periodontal disease is an infection affecting the tooth supporting tissues. The main etiology of the disease is bacterial plaque attached to tooth surfaces. In its early stage, the gum become swollen, red and may bleed upon stimulation, i.e. tooth brushing or spontaneously. This condition is called gingivitis, which inflammation is still limited in the gingival tissue. To date back, an acute condition of gingival inflammation with distinct figure of necrotic 'punched' interdental papilla, accompanied by spontaneous bleeding and pain, was well documented during World War II, affecting soldiers as an epidemic. ${ }^{12}$ This condition, known as Vincent's angina, Trench mouth or Necrotizing Ulcerative Gingivitis (NUG), was investigated on the suggestion of the Director General of the Army Medical Services (DGAMS) and the Pathological Committee of the War Office from patients in military hospitals in England during the period from July 1918 to April 1919. To this day, NUG is still seen in the British army. ${ }^{13}$ Opportunistic fusospirochetal infection resulting from the commensal oral flora is the main cause of NUG, predisposed by diminished immune system. ${ }^{14}$

If not treated, gingivitis may progress to periodontitis. The inflammation spreads widely affecting the underlying tissues, i.e. periodontal ligament, cementum and alveolar bone. Clinical signs of the disease are deepening of the pocket and tooth mobility. Untreated periodontitis is the most common cause of tooth loss among adults. ${ }^{15,16}$

Periodontitis is a multifactorial disease; in principle it is caused by an imbalance between environmental factors and the host defense. The environmental factors include the infectious component (bacterial pathogens) in dental plaque and unfavorable life-style factors and living conditions. The innate immunity in host response may be hyper-reactive resulting in an exuberant 
inflammatory response. In addition, malnutrition, genetic and certain systemic diseases can impair the host defense and therefore may play a role in the development of the disease. The pathogenic bacteria that have been associated in periodontal disease include Aggregatibacter actinomycetemcomitans, Porphyromonas gingivalis, Prevotella intermedia, Tannerella forsythia, Fusobacterium nucleatum, Parvimonas micra and Treponema denticola. 17,18,19 In addition, virus infections have been suggested to be related to periodontitis. ${ }^{20}$

Taking into consideration that some factors are related to periodontal disease, military way of life may have influences on the prevalence and progression of periodontal disease as described below :

\section{Inadequate Oral Hygiene and Irregular Maintenance Care}

Studies showed that the prevention of periodontal disease requires improved oral hygiene. Public health experts have attempted to develop educational programs which stress the importance of adequate professional and personal health care services. Proper oral hygiene may services. Proper oral hygiene may resolve gingivitis and prevent progression of periodontal disease. ${ }^{21,22}$ Repeated maintenance care once in every 2-3 months which was included instruction and practice of oral hygiene techniques as well as meticulous prophylaxis was successful in prevention of periodontal disease compared to traditional dental care providing sporadic periodontal treatment. In a cohort of young Navy personnel, with over 98 percent of the study population exhibited some level of periodontal disease at initial examination, gradual deterioration over time was markedly found in subjects with irregular maintenance care. ${ }^{23}$ The lack of adequate oral hygiene may facilitate plaque redevelopment and recolonization, resulting in accumulation of bacterial plaque detrimental to the periodontal tissue. ${ }^{24}$

Utilization of military dental services is not in optimal level yet, since most of the personnel would come when they have dental problem such as toothache or painful condition. ${ }^{25}$ In some regions, regular dental check-up is not a norm among them, even in the peacetime status. Most of them are symptomatic attendees who only visited the dentist to relieve pain and after an emergency visit, they would not come for any maintenance cares.

In wartime, military maneuvers may avoid their personnel from performing normal oral hygiene. Moreover, oral maintenance care may be neglected due to operational circumstances and absence of normal life. Failure to properly remove plaque from the teeth and gingiva for a week or more usually results in the development of gingivitis in response to bacterial dental plaque. Worsening of the average periodontal condition after 6 months of deployment was seen in soldiers deployed to Iraq. ${ }^{26}$ Under extremely difficult conditions, soldiers did not attend regular dental visits, brushed their teeth infrequently, which led to a tendency towards the deterioration of oral health with an increase in time spent on battlefields. ${ }^{27} \mathrm{~A}$ study in 912 Croatian soldiers revealed that the oral health of the examined population was mostly poor, as a consequence of inadequate prevention of illnesses of the oral cavity associated with insufficient oral hygiene. ${ }^{3}$ Such condition makes most of the soldiers unreliable for peace operations that would last 6 months, because it lowers their combat readiness.

\section{Stress}


Stress has been related to the onset and progression of periodontal disease. ${ }^{28}$ Currently, stress is classified as a 'risk indicator' for periodontal disease. Stress impairs periodontal health through changes in behavior and complex interactions among the nervous, endocrine, and immune systems. Since oral diseases are behaviour-related, some changes in the oral cavity could be expected. Mechanisms through physiologic pathways may influence periodontal tissues through alteration in saliva, changes in gingival blood circulation, endocrine imbalances, and altered host resistance. Moreover, psychological stress can down-regulate the cellular immune response. Communication between the central nervous system and the immune system occurs through a complex network of bidirectional signals. One of the important markers of psychological stress is cortisol, it depress immunity by inhibiting the production of secretory immunoglobulin $A$ and $G(\lg A, \lg G)$, and neutrophil functions, all of which may impair defense against infection by periodontal microorganisms. Hilgert et al (2006) evaluated the extent and severity of chronic periodontitis and its association with the levels of cortisol and the scores of an inventory of stress symptoms in a population aged $>50$ years. ${ }^{29}$ The results showed a positive association between cortisol levels and extent and severity of periodontitis. A cross-sectional pilot study reported by Rosania et al (2009) explored the associations between stress, markers of periodontal disease, psycho-neuro-immunologic variables and behavior. The results of this study suggested that stress and salivary cortisol are important correlates of periodontal disease. ${ }^{30}$ Military personnel are exposed to specific psychological, physical and environmental conditions, not only in war, but also in peacetime. The most notable example is the documented relationship between stress and necrotizing ulcerative gingivitis (NUG) during military service. This condition probably predisposed by favoring bacterial overgrowth and/or weakening host resistance. ${ }^{31}$ Immune system may be diminished by mechanisms acting through the autonomic nervous system and endocrine glands resulting in elevation of corticosteroid and catecholamine levels. It has been reported that NUG patients as compared to healthy subjects presented defective function of polymorphonuclear leukocyte i.e. chemotaxis and phagocytosis; and reduced proliferation of lymphocytes upon stimulation by a nonspecific antigen. NUG patients were also more stressed than healthy subjects, with increased corticosteroid activity, suggesting that depression of some host defense mechanisms, under stress conditions, may be necessary in the pathogenesis of NUG. ${ }^{32,33}$

\section{Nutrition}

In addition to poor living conditions, several major risk factors relate to unhealthy lifestyles. One of important lifestyle factors associated with periodontal disease is nutrition. ${ }^{34}$ There is evidence to suggest that periodontal disease progresses more rapidly in undernourished populations and the important role of nutrition in maintaining an adequate host immune response may explain this observation. ${ }^{35}$

Periodontal disease results from the loss of a delicate balance between microbial virulence factors and a proportionate host response. Innate and adaptive defenses of the host, including phagocytic function, cell mediated immunity, complement system, secretory antibody, and cytokine production and function were impaired by 
malnutrition. ${ }^{36}$ Prolonged malnutrition could modify the response of human gingival and periodontal tissues to local irritants. ${ }^{37}$ In addition, oral microbial ecology was markedly changed, resulting in a pathogenic anaerobic bacteria predominance, increased predisposition of bacteria to bind to oral mucosal cells, attenuation of acute phase protein response, and dysfunction of the cytokine system. ${ }^{38}$ This depleted condition in nutrients is associated with a progressive damage to the mucosa, lowered immunity, and a diminished resistance to colonization and invasion by potential pathogens. ${ }^{39}$ One distinctive features of malnutrition in oral cavity is the evidence of NUG in impoverished African children who are generally immune-compromised by malnutrition and common tropical infections. If not promptly treated, NUG and other oral inflammatory lesions may evolve into noma (cancrum oris). 40

Tissue and cellular depletion of key nutrients is often markedly occurring in malnutrition, particularly the major antioxidant nutrients. Cellular depletion of antioxidant nutrients promotes immunosuppression, accelerated replication rate of ribonucleic acid viruses and increased disease progression. ${ }^{35}$

Nutrients can be classified into six major classes: carbohydrates, fats, minerals, protein, vitamins, and water. These nutrient classes can be categorized as either macronutrients (needed in relatively large amounts) or micronutrients. Micronutrients are dietary compounds, such as vitamins, minerals, trace elements, amino acids, poly-unsaturated fatty acids (PUFA) that are required only in small quantities (micrograms or milligrams per day) by living organisms and are essential for optimal health, proper growth, and metabolism.
Low micronutrient levels in plasma/serum is associated with periodontitis. One of micronutrients that have been associated with periodontitis is vitamin C. The importance of vitamin C for periodontal health has been known for quite some time. Insufficient consumption of vegetables and fruits, the two major sources of vitamin $\mathrm{C}$, can lead to depletion or deficiency states for the vitamin. ${ }^{41,42}$ Severe vitamin $C$ deficiency and malnutrition may result in aggravated periodontal disease conditions. In addition, evidence shows that plasma vitamin $\mathrm{C}$ levels are inversely related to the severity of periodontitis. ${ }^{43,44,45}$

Malnutrition may occur in extremely difficult condition during war. Meals were less frequent (on average twice a day) and canned food was the only one available. ${ }^{27}$ Imbalanced food intake may lead to depletion of micronutrients that is essential for optimal health and metabolism. Fresh vegetables and fruits are scarce, resulting in depletion or deficiency states for the vitamin. This condition may depress immune system and dysregulate various parameters of the host system, which is in turn increased vulnerability of the periodontal tissues to inflammatory stimuli from dental plaque.

\section{Smoking}

Another most important lifestyle factors related to the development and severity of periodontal disease is smoking. Depending on the definition of disease and the exposure to smoking, the risk to develop destructive periodontal disease is 5 - to 20 fold elevated for a smoker compared to a neversmoker, regardless of levels of plaque accumulation. ${ }^{46}$ Chronic and heavy smoking can reduce gingival bleeding and therefore mask the clinical marker of bleeding on probing often used by dentists to monitor periodontal health. ${ }^{47}$ This has 
implications for potential misdiagnosis and failure to detect periodontitis at an early stage.

Several studies have shown that prolonged smoking increased periodontal disease sites concomitant with loss of periodontal bone height. ${ }^{48,49}$ It was hypothesized that smoking altered the microbiota composition, diminished immune response, and reduced healing capacity of the periodontium. The mechanism on which smoking may have detrimental effects to periodontal health is that smoking lead to a shift in the composition of the subgingival biofilm with an increase in the prevalence of periodontal pathogens. ${ }^{50}$ Moreover, smoking has been implicated in the delay of neutrophils recruitment and migration into periodontal tissues, thus compromising the acute immune response. ${ }^{51}$ This fact would increase the threshold of aggression necessary to the periodontal tissue to initiate the inflammatory cascade. In addition, it has been suggested that smoke would shift the balance of neutrophil activities to a more destructive nature. ${ }^{52}$

Current smokers were correlated with a high prevalence of aggressive periodontitis among Israeli Army personnel . ${ }^{53}$ The higher prevalence of tobacco habit was found among young army personnel than older and there was a significant association of smoking and periodontal disease. ${ }^{54}$

In a survey conducted in 1980-2005, cigarette smoking in military service members was increased significantly between 1998 and 2002.55 Possible explanations for this higher military tobacco use include greater exposure to tobacco, peer pressure, stress, boredom, inexpensive cigarettes, and lack of other forms of recreation. Many recruits began to smoke after entering the military. $56,57,58$ In another study, there were $57 \%$ ex-smokers who had quit and then resumed the habit after entering the military. .59

Increasing rate of smoking during military deployment was evidenced. 60,61 Among 556 British Armed Forces during their sixth week of deployment to Iraq, $29 \%$ reported that they had smoked before deployment, but by 6 weeks into deployment this number had increased to $38 \% .^{62}$ In a study evaluated smoking behaviors involving 150 U.S. primarily Marines and Navy personnel deployed to Iraq, only $36 \%$ of those interviewed indicated smoking prior to their deployment, but more than half $(56 \%)$ reported smoking during deployment. ${ }^{63}$ Barton et al. 2010 revealed a pattern toward increased rates of smoking when deploying to a combat zone followed by declines in smoking upon returning to post-deployment status. The majority of the respondents reporting smoking during deployment increased their tobacco use while deployed (59\%), and a larger group (81\%) expressed their intent to stop smoking upon returning to the United States. ${ }^{64}$

The stress of military deployment may compound occupational stress experienced in the military and manifest in maladaptive coping behaviors such as cigarette smoking. Smoking is perceived as a stress relief, a calming agent and a status elevator. Military personnel are at high risk for tobacco use, taking into account that military work environment cause work stress and depression in military employees. ${ }^{65}$

\section{DISCUSSION}

Oral health is important for military personnel who deploy around the world in military operations or peacekeeping service. Dental emergencies, as defined as a condition of oral disease, trauma or loss of function or other condition that causes 
patient to seek immediate dental treatment, can be prevented by maintenance of good oral health. In order to screen the military population, NATO has established a system of Dental Fitness Standards. The system identifies those military members dentally fit for an overseas deployment where dental resources may be limited. ${ }^{66}$

The rate of dental emergencies is higher for units whose soldiers deploy with poor oral health. If they are not prevented or treated early, oral diseases can cause severe, life-threatening illness and may even require medical evacuation from deployment. To prevent the worsening of periodontal disease, e.g. acute gingivitis, soldier must improve oral hygiene and use an antimicrobial mouth rinse. In the case of extreme gingival tenderness, soldiers may be encouraged to reestablish oral hygiene procedures using viscous lidocaine on their toothbrushes rather than a dentifrice. Noncommissioned officers should ensure that the oral hygiene routine of all troops includes toothbrushing, at least once daily at a minimum, preferably twice daily, with fluoride toothpaste to prevent dental caries and gingival problems; rinsing several times a week with an antimicrobial mouthwash containing thymol or chlorhexidine gluconate (for those with chronic periodontal conditions). ${ }^{67}$ In addition, the use of chewing gum or lozenge that contains probiotic as the active ingredient in navy sailors at sea, prevents dental decay and periodontal disease, even in the situations with diminished efficacy of personal oral hygiene, as it helps the good microorganism keep a natural balance in the oral cavity. 68 The assigned chewing gum may be distributed in theater dining facilities in the accessory pack of the MRE (meal, ready-to-eat).

The stress of deployment may change some behavior. ${ }^{69}$ Since periodontal disease is related to behavior, unfavorable changes in behavior may have detrimental effect on periodontal health. During deployment or other stressful conditions, dietary habit may change and leads military members to suffer from nutrition deficiency and dehydration. ${ }^{70}$ Since the oral epithelium relies on micronutrients and hydration to continually performs high rate of cellular turnover, these deficiencies can affect oral health by preventing repairing and renewing itself. ${ }^{71}$ These conditions may be manifestated in oral cavity as glossitis, angular cheilitis, stomatitis and gingivitis. ${ }^{72}$ Furthermore, increased progression of periodontitis is also associated with malnutrition since several micronutrients i.e. vitamins $\mathrm{A}, \mathrm{B}, \mathrm{C}, \mathrm{D}, \mathrm{E}$ and minerals such as zinc, iron, magnesium and calcium are important for repairing and renewing oral epithelium and periodontal attachment ensuring an adequate amount of saliva, as a defense against oral disease, in sufficient quality to protect the oral cavity. Stressful circumferences may compromise saliva composition or flows which in turn may impair antifungal, antiviral and actibacterial properties. ${ }^{73}$

Soldiers should be trained in stress reducing techniques to avoid these problems (as well as the many other negative effects of combat stress). Stress relieving activities may include exercise, art/music therapies, dancing, mindfulness, yoga and engaging with nature, as it have been proven to reduce stress and enhance well-being. ${ }^{74}$ The pattern cortisol secretion, which are regulated by the brain, are a key mediator of stress and wellbeing links. ${ }^{75}$ Cortisol is secreted as a response of negative feedback, during situation perceived as stressful via the hypothalamic-pituatary-adrenal (HPA) axis. Nowadays, stress-relieving strategies included positive psychological intervention such as expressing gratitude, identifying and using personal strength or writing about the good things in 
someone's life, have been shown to reduce stress and enhance well-being among adults. ${ }^{76}$ Moreover, physical exercise, art and music therapies, dancing in groups, yoga practice and exposure to nature have been proven to help people coping with stress. ${ }^{77}$

When smoking is used as a coping mechanism for stress, the magnitude of tissue destruction will be escalated. A military dentist should be engaged in tobacco intervention efforts. Tobacco intervention includes tobacco cessation activities, prevention, and public policy development. The intervention is called 5 A, Ask, Advice, Assess, Assist and Arrange. Ask patients about smoking and during every visit, every patient is asked about tobacco use, and the answer is documented in the patient's record. Advise all smokers to stop. A military dentists should demonstrate the oral effects of tobacco if present, or inform patients about the increased risk of poor response or healing after dental procedures relevant to the patient. Assess the patient's willingness to stop. If the patient is willing to make an attempt to quit, dentists should assist the patient. If the patient is unwilling to quit, the military dentist should accept the patient's decision and make a note in the record for future reference or the patient can be referred to a tobacco cessation specialist (if available). Assist the patient in stopping. If a patient has a desire to stop, the dentist should help the patient set a realistic quitting date which should be soon but not immediately so that the patient has time to prepare. Nicotine replacement therapy (nicotine patch, nicotine gum, inhaler or nasal spray) can be very helpful. ${ }^{78}$ Recently, an alternative method to help smokers unwilling to quit, called Tobacco Harm Reduction, is suggesting reduced-risk products, i.e. Electronic Nicotine Delivery Systems (ENDS), heated tobacco products and Snus, that is considered to be less harmful than combustible cigarettes. ${ }^{79}$ Study finds that military services members smoke at a lesser rate than the general population and that 11.1 percent of military service members report daily ecigarette use. ${ }^{80}$ Arrange follow-up contact, it is very important as the chances of a successful outcome are improved when patients know their progress will be reviewed. The dentist should confirm the quitting date, show continuing support, and encourage another try if unsuccessful.

\section{CONCLUSION}

From the review aforementioned, it may be concluded that despite the integrated programs to decline dental decay prevalence, preventive dentistry services and periodontal therapy should be provided early in the military careers and repeated at intervals specific to the needs of each patient. Several risk factors related to military way of life that contributing to the development and severity of periodontal disease should be assessed and overcome to arrest the progression of the disease.

\section{ACKNOWLEDGEMENTS}

The authors greatly acknowledge Head of Indonesian Naval Dental Institute RE Martadinata (LADOKGI), Jakarta, Indonesia, Colonel Dr. Ganesha Wandawa, DDS, Periodontist and Head of Naval Dental Hospital, Jakarta, Colonel Sugeng Winarno, DDS, MKM, Periodontist for research collaboration and supporting advice in the writing of this literature study.0

\section{REFERENCES}

1. Chaffin J, King JE, Fretwell LD. US Army dental emergency rates in Bosnia. Military Medicine. 2001; 1;166(12):1074-8. 
2. Bishop BG, Donnelly JC. Proposed criteria for classifying potential dental emergencies in Department of Defense military personnel. Military Medicine. 1997; 1;162(2):130-5.

3. Škec V, Macan JŠ, Sušac $M$, Jokić $D$, Brajdić D, Macan D. Influence of oral hygiene on oral health of recruits and professionals in the Croatian Army. Military Medicine. 2006; 1;171(10):1006-9.

4. Hopcraft M, Morgan M. Dental caries experience in a young adult military population. Australian Dental Journal. 2003; 1;48(2):125-9.

5. Hyman JJ, Reid BC, Mongeau SW, York AK. The military oral health care system as a model for eliminating disparities in oral health. The Journal of the American Dental Association. 2006; 1;137(3):372-8.

6. Katz J, Peretz B, Sgan-Cohen HD, Horev T, Eldad A. Periodontal status by CPITN, and associated variables in an Israeli permanent force military population. Journal of Clinical Periodontology. 2000; 1;27(5):319-24.

7. Grewal $Y$ \& Evans W. Dental fitness of Indian army soldiers. Journal of Pharmaceutical and Biomedical Sciences. 2014; 04(05):375-381.

8. Yousaf A, Manzoor MA, Rafi S, Yousaf N, Shabbir SM. Frequency of gingival and periodontal diseases among troops deployed in operational area. Pakistan Armed Forces Medical Journal. 2014; $1(1): 92$.

9. Kovačević $\mathrm{V}$, Milosavljević $M$, Rančić $N$, Daković D. Assessment of the periodontal health and community periodontal index in the Army of Serbia. Vojnosanitetski Pregled. 2015;72(11):953-60.

10. Sutthavong $S$, Cae-ngow $S$, Rangsin $R$. Oral health survey of military personnel in the Phramongkutklao Hospital, Thailand. Journal of the Medical Association of Thailand. 2011; 11;92(2):84.

11. Chrysanthakopoulos NA. Periodontal reasons for tooth extraction in a group of greek army personnel. Journal of Dental Research, Dental Clinics, Dental Prospects. 2011;5(2):55.

12. Pindborg JJ. Influence of service in armed forces on incidence of gingivitis. The Journal of the American Dental Association. 1951;1;42(5):517-22.

13. Dufty JR. Report for the pathological committee of the war office of an inquiry into gingivitis and Vincent's disease occurring in the Army. Journal of the Royal Army Medical Corps. 2014;160:i7.

14. Loesche WJ, Syed SA, Laughon BE, Stoll $\mathrm{J}$. The bacteriology of acute necrotizing ulcerative gingivitis. Journal of Periodontology. 1982; 1;53(4):223-30.

15. Page RC. Gingivitis. Journal of Clinical Periodontology. 1986; 1;13(5):345-55.

16. Löe H, Anerud A, Boysen H, Morrison E. Natural history of periodontal disease in man. Journal of Clinical Periodontology. 1986;13(5):431-40.

17. Slots J, Ting M. Actinobacillus actinomycetemcomitans and Porphyromonas gingivalis in human periodontal disease: occurrence and treatment. Periodontology 2000. 1999; 1;20(1):82-121.

18. Socransky SS, Haffajee AD. Dental biofilms: difficult therapeutic targets. Periodontology 2000. 2002; 1;28(1):12-55.

19. Van Winkelhoff AJ, Loos BG, Van Der Reijden WA, Van Der Velden U. Porphyromonas gingivalis, Bacteroides forsythus and other putative periodontal pathogens in subjects with and without periodontal destruction. Journal of Clinical Periodontology. 2002; 1;29(11):1023-8.

20. Slots J. Human viruses in periodontitis. Periodontology 2000. 2010; 1;53(1):89110.

21. Axelsson P, Lindhe J. Effect of controlled oral hygiene procedures on caries and periodontal disease in adults. Journal of Clinical Periodontology. 1981; 1;8(3):23948.

22. Axelsson P, Lindhe J, Nyström B. On the prevention of caries and periodontal disease. Journal of Clinical Periodontology. $1991 ; 1 ; 18(3): 182-9$.

23. Diefenderfer KE, Ahlf RL, Simecek JW, Levine ME. Periodontal health status in a cohort of young US Navy personnel. Journal of Public Health Dentistry. 2007; $1 ; 67(1): 49-54$.

24. Uzel NG, Teles FR, Teles RP, Song $X Q$, Torresyap G, Socransky SS, Haffajee AD. Microbial shifts during dental biofilm redevelopment in the absence of oral hygiene in periodontal health and disease. Journal of Clinical Periodontology. 2011; 1;38(7):612-20.

25. Supreetha S, Prathima K, Sam G, Penumatsa NV, Khanapure S, Jagadeesh $\mathrm{KN}$. Utilization of dental services and oral health status among police personnel in Virajpet, South India. International Journal 
of Oral Care and Research 2016; 4(2) : 8790.

26. Wojcik BE, Szeszel-Fedorowicz W, Humphrey RJ, Colthirst $P$, Guerrero AC, Simecek JW, Fedorowicz A, Eikenberg S, Rogers GG, DeNicolo P. Risk of dental disease non-battle injuries and severity of dental disease in deployed US Army personnel. Military Medicine. 2015; 1;180(5):570-7.

27. Suman M, Spalj S, Plancak D, Dukic W, Juric $\mathrm{H}$. The influence of war on the oral health of professional soldiers. International Dental Journal. 2008; 1;58(2):71-4.

28. Genco RJ, Ho AW, Kopman J, Grossi SG, Dunford RG, Tedesco LA. Models to evaluate the role of stress in periodontal disease. Annals of Periodontology. 1998;3(1):288-302.

29. Hilgert JB, Hugo FN, Bandeira DR, Bozzetti MC. Stress, cortisol, and periodontitis in a population aged 50 years and over. Journal of dental research. 2006;85(4):324-8.

30. Rosania AE, Low KG, McCormick CM, Rosania DA. Stress, depression, cortisol, and periodontal disease. Journal of Periodontology. 2009;80(2):260-6.

31. Reners M, Brecx M. Stress and periodontal disease. International Journal of Dental Hygiene. 2007; 1;5(4):199-204.

32. Shannon IL, Kilgore WG, O'Leary TJ. Stress as a predisposing factor in necrotizing ulcerative gingivitis. Journal of Periodontology. 1969;40(4):240-2.

33. Cogen RB, Stevens Jr AW, Cohen-Cole S, Kirk K, Freeman A. Leukocyte function in the etiology of acute necrotizing ulcerative gingivitis. Journal of Periodontology. 1983;54(7):402-7.

34. Van der Velden U, Kuzmanova D, Chapple IL. Micronutritional approaches to periodontal therapy. Journal of Clinical Periodontology. 2011; 1;38(s11):142-58.

35. Moynihan P, Petersen PE. Diet, nutrition and the prevention of dental diseases. Public Health Nutrition. 2004;7(1a):201-26.

36. Bhaskaram P. Micronutrient malnutrition, infection, and immunity: an overview. Nutrition reviews. 2002; $1 ; 60$ (s5).

37. Enwonwu CO. Cellular and molecular effects of malnutrition and their relevance to periodontal diseases. Journal of Clinical Periodontology. 1994;1;21(10):643-57 .

38. Tabak, L. A. \& Bowen, W. H. Roles of saliva (pellicle), diet, and nutrition on plaque formation. Journal of Dental Research. 1989; $68: 1560-1566$.

39. Chandra RK. McCollum Award lecture. Nutrition and immunity: lessons from the past and new insights into the future. American Journal of Clinical Nutrition (USA). 1991.

40. Folayan MO. The epidemiology, etiology, and pathophysiology of acute necrotizing ulcerative gingivitis associated with malnutrition. Journal of Contemporary Dental Practice. 2004;15;5(3):28-41.

41. Taylor CA, Hampl JS, Johnston CS. Low intakes of vegetables and fruits, especially citrus fruits, lead to inadequate vitamin $C$ intakes among adults. European Journal of Clinical Nutrition. 2000; 54(7):573.

42. Wrieden WL, Hannah MK, Bolton-Smith C, Tavendale R, Morrison C, Tunstall-Pedoe $\mathrm{H}$. Plasma vitamin $C$ and food choice in the third Glasgow MONICA population survey. Journal of Epidemiology \& Community Health. 2000; 1;54(5):355-60.

43. Amarasena N, Ogawa $H$, Yoshihara $A$, Hanada N, Miyazaki H. Serum vitamin Cperiodontal relationship in communitydwelling elderly Japanese. Journal of Clinical Periodontology. 2005; 1;32(1):937.

44. Amaliya, Timmerman MF, Abbas F, Loos BG, Van der Weijden GA, Van Winkelhoff AJ, Winkel EG, Van der Velden U. Java project on periodontal diseases: the relationship between vitamin $C$ and the severity of periodontitis. Journal of Clinical Periodontology. 2007;34(4):299-304.

45. Chapple IL, Milward MR, Dietrich T. The prevalence of inflammatory periodontitis is negatively associated with serum antioxidant concentrations. The Journal of Nutrition. 2007; 1;137(3):657-64.

46. Bergström J. Tobacco smoking and chronic destructive periodontal disease. Odontology. 2004; 1;92(1):1-8.

47. Dietrich T, Bernimoulin JP, Glynn RJ. The effect of cigareté smoking on gingival bleeding. Journal of periodontology. 2004; 1;75(1):16-22.

48. Bergström J, Eliasson S, Dock J. A 10-year prospective study of tobacco smoking and periodontal health. Journal of Periodontology. 2000; 1;71(8):1338-47.

49. Albandar JM, Streckfus CF, Adesanya MR, Winn DM. Cigar, pipe, and cigarette smoking as risk factors for periodontal disease and tooth loss. Journal of Periodontology. 2000; 1;71(12):1874-81. 
50. Sreedevi M, Ramesh A, Dwarakanath C. Periodontal status in smokers and nonsmokers: a clinical, microbiological, and histopathological study. International Journal of Dentistry. 2012.

51. Persson L, Bergström J, Ito H, Gustafsson A. Tobacco smoking and neutrophil activity in patients with periodontal disease. Journal of Periodontology. 2001; 1;72(1):90-5.

52. Gonçalves RB, Coletta RD, Silvério KG, Benevides L, Casati MZ, Da Silva JS, Nociti $\mathrm{FH}$. Impact of smoking on inflammation: overview of molecular mechanisms. Inflammation Research. 2011;1;60(5):40924.

53. Levin L, Baev V, Lev R, Stabholz A, Ashkenazi M. Aggressive periodontitis among young Israeli army personnel. Journal of Periodontology. 2006; 77(8):1392-6.

54. Ahuja A, Singh BN. Assessment of disease burden among army personnel and dependents in Lucknow city. Journal of Indian Association of Public Health Dentistry. 2015; 1;13(1):14.

55. Bray RM, Hourani LL. Substance use trends among active duty military personnel: findings from the United States Department of Defense Health Related Behavior Surveys, 1980-2005. Addiction. 2007; 1;102(7):1092-101.

56. Cronan TA, Conway TL. Is the Navy attracting or creating smokers?. Military Medicine. 1988; 1;153(4):175-8.

57. Conway TL. Tobacco use and the United States military: a longstanding problem. Tobacco Control. 1998; 7 : 219-221.

58. Cronan TA, Conway TL, Kaszas SL. Starting to smoke in the Navy: when, where and why. Social Science \& Medicine. 1991; 1;33(12):1349-53.

59. Shahar Y, Carel RS. Changes in smoking patterns in young military recruits in relationship to psychosocial characteristics. Military Medicine. 1991;1;156(9):455-61.

60. Forgas LB, Meyer DM, Cohen ME. Tobacco use habits of naval personnel during Desert Storm. Military Medicine. 1996; 1;161(3):165-8.

61. Talcott GW, Cigrang J, Sherrill-Mittleman D, Snyder DK, Baker M, Tatum J, Cassidy D, Sonnek S, Balderrama-Durbin C, Klesges RC, Ebbert JO. Tobacco use during military deployment. nicotine \& tobacco research. 2013; 8;15(8):1348-54.

62. Boos CJ, Croft AM. Smoking rates in the staff of a military field hospital before and after wartime deployment. Journal of the Royal Society of Medicine. 2004;97(1):202.

63. Di Nicola M, Occhiolini L, Di Mascio R, Vellante $\mathrm{P}$, Colagrande V, Ballone $\mathrm{E}$. Smoking habits in a sample of young Italian soldiers. Military Medicine. 2006;1;171(1):69-73.

64. Barton CA, McGuire A, Waller M, Treloar SA, McClintock C, McFarlane AC, D'Este C. Smoking prevalence, its determinants and short-term health implications in the Australian Defence Force. Military Medicine. 2010; 1;175(4):267-72.

65. Pflanz SE, Ogle AD. Job stress, depression, work performance, and perceptions of supervisors in military personnel. Military Medicine. 2006;1;171(9):861-5.

66. Groves, RR. Dental fitness classification in the Canadian forces. Military Medicine 2008; 173 , suppl 1: 18-22.

67. Eliasson, A., Kashani, M., Dela Cruz, G., \& Vernalis, M. Readiness and associated health behaviors and symptoms in recently deployed Army National Guard solders. Military Medicine. 2012; 177(11) :12541260.

68. Schlagenhauf, U., Rehder, J., Gelbrich, G., \& Jockel-Schneider, Y. Consumption of Lactobacillus reuteri-containing lozenges improves periodontal health in navy sailors at sea: $A$ randomized controlled trial. Journal of Periodontology. 2020; 91(10), 1328-1338.

69. Deinzer, R., Granrath, N., Spahl, M., Linz, S., Waschul, B., \& Herforth, A. Stress, oral health behaviour and clinical outcome. British Journal of Health Psychology. 2005; 10(2) : 269-283.

70. Breland, J. Y., Donalson, R., Nevedal, A., Dinh, J. V., \& Maguen, S. Military experience can influence Women's eating habits. Appetite. 2017; $118: 161-167$.

71. Radler, D. R., \& Lister, T. Nutrient deficiencies associated with nutritionfocused physical findings of the oral cavity. Nutrition in Clinical Practice. 2013; 28(6): 710-721.

72. Sheetal, A., Hiremath, V. K., Patil, A. G., Sajjansetty, S., \& Kumar, S. R. Malnutrition and its oral outcome-a review. Journal of Clinical and Diagnostic Research: JCDR. 2013; 7(1): 178.

73. Bulthuis, M. S., Jager, D. H. J., \& Brand, H. S. Relationship among perceived stress, xerostomia, and salivary flow rate in 
patients visiting a saliva clinic. Clinical Oral Investigations. 2018; 22(9): 3121-3127.

74. Smyth, N., Rossi, E., \& Wood, C. Effectiveness of stress-relieving strategies in regulating patterns of cortisol secretion and promoting brain health. Stress and Brain Health: Across the Life Course. 2020; 219.

75. Clow, A., Edwards, S., Owen, G., Evans, G., Evans, P., Hucklebridge, F., \& Casey, A. Post-awakening cortisol secretion during basic military training. International Journal of Psychophysiology. 2006; 60(1): 88-94.

76. Cavanagh, K., Strauss, C., Forder, L., \& Jones, F. Can mindfulness and acceptance be learnt by self-help?: A systematic review and meta-analysis of mindfulness and acceptance-based self-help interventions. Clinical Psychology Review. 2014; 34(2):118-129.

77. Gerber, M., Brand, S., Elliot, C., HolsboerTrachsler, E., \& Pühse, U. Aerobic exercise, ball sports, dancing, and weight lifting as moderators of the relationship between stress and depressive symptoms: An exploratory Cross-sectional study with
Swiss university students. Perceptual and Motor Skills. 2014; 119(3): 679-697.

78. Reibel, J. Tobacco and oral diseases. Medical principles and practice. 2003; 12(Suppl. 1): 22-32.

79. Polosa, R., Caponnetto, P., Morjaria, J. B., Papale, G., Campagna, D., \& Russo, C. Effect of an electronic nicotine delivery device (e-Cigarette) on smoking reduction and cessation: a prospective 6-month pilot study. BMC public health 2011; 11(1), 786.

80. Meadows, S. O., Engel, C. C., Collins, R. L., Beckman, R. L., Cefalu, M., HawesDawson, J., ... \& Williams, K. M. 2015 Department of Defense Health Related Behaviors Survey (HRBS). Rand Health Quarterly. 2018; 8(2). 